\title{
Correlation of the Rates of Solvolysis of 4-Morpholinecarbonyl Chloride Using the Extended Grunwald-Winstein Equation
}

\author{
Ran Kim, Dildar Ali, ${ }^{\dagger}$ Jong Pal Lee, ${ }^{\ddagger, *}$ Kiyull Yang, and In Sun Koo* \\ Department of Chemistry Education and Research Instituted of Natural Science, Gyeongsang National University, \\ Jinju660-701, Korea. *E-mail: iskoo@gnu.ac.kr \\ ${ }^{\dagger}$ Institute of Biochemistry, University of Balochistan, Quetta, Pakistan \\ ${ }^{\star}$ Department of Chemistry, Dong-A University, Pusan 604-714, Korea. *E-mail: jplee@dau.ac.kr \\ Received April 21, 2010, Accepted May 19, 2010
}

\begin{abstract}
The rates of solvolysis of 4-morpholinecarbonyl chloride (MPC) have measured at $35.0{ }^{\circ} \mathrm{C}$ in water, $\mathrm{D}_{2} \mathrm{O}, \mathrm{CH}_{3} \mathrm{OD}$, and in aqueous binary mixtures of acetone, ethanol, methanol, and 2,2,2-trifluoroethanol. An extended (two-term) Grunwald-Winstein equation correlation gave sensitivities towards changes in solvent nucleophilicity and solvent ionizing power as expected for a dissociative $\mathrm{S}_{\mathrm{N}} 2$ and/or $\mathrm{S}_{\mathrm{N}} 1$ (ionization) pathway. For nine solvents specific rates were determined at two additional temperatures and higher enthalpies and smaller negative entropies of activation were observed, consistent with the typical dissociative $\mathrm{S}_{\mathrm{N}} 2$ or $\mathrm{S}_{\mathrm{N}} 1$ (ionization) pathway. The solvent deuterium isotope effect values for the hydrolysis of MPC of $k_{\mathrm{H}_{2} \mathrm{O}} / k_{\mathrm{D}_{2} \mathrm{O}}=1.27$ and for the methanolysis of MPC of $k_{\mathrm{MeOH}} / k_{\mathrm{MeOD}}=1.22$ are typical magnitudes of the $\mathrm{S}_{\mathrm{N}} 1$ or ionization mechanism.
\end{abstract}

Key Words: 4-Morpholinecarbonyl chloride (MPC), Grunwald-Winstein equation, Addition-elimination (A-E), Ionization (I), KSIE

\section{Introduction}

The Grunwald-Winstein equation (eq. 1) is very useful tool for mechanistic study of the solvolyses of substrates in various binary solvent mixtures. ${ }^{1}$ In eq. (1), $k$ and $k_{0}$ are the rates of solvolysis of a substrate RX in a given solvent and in the standard solvent ( $80 \%$ ethanol), respectively; $m$ represents the sensitivity to changes in solvent ionizing power $Y_{\mathrm{Cl}}{ }^{2}$ and $c$ represents a constant (residual) term. However, dispersion into separated lines in the correlation of the specific rates of solvolysis of benzoyl $^{3}$ and sulfonyl halides in various aqueous solvents mixtures was documented ${ }^{4}$ in early treatments using the Grunwald-Winstein eq. (1).

$$
\log \left(k / k_{0}\right)=m Y_{\mathrm{Cl}}+c
$$

In general, dispersion effects in unimolecular solvolysis ${ }^{5}$ make smaller contributions to the overall linear free energy relationship (LFER) than solvent nucleophilicity effects in bimolecular solvolysis. ${ }^{4(a), 6,7}$ Therefore, it was suggested that a second term which is governed by sensitivity $l$ to the solvent nucleophilicity $N$, should be added in eqn. (1) for bimolecular solvolysis. ${ }^{7}$ The resulting eq. (2) is often referred to as the extended Grunwald-Winstein equation. The eqn. (2) has proven extremely valuable in studies of the mechanism of solvolyses reaction.

$$
\log \left(k / k_{0}\right)=l N_{\mathrm{T}}+m Y_{\mathrm{Cl}}+c
$$

For an ionization reaction without nucleophilic assistance, $l$ will be zero and $m$ closes to unity. For an addition-elimination reaction pathway with extensive nucleophilic assistance, the $l$ value will be greater than 1.5 and the $m$ value will be less than
0.5. ${ }^{9}$ Solvolysis of benzoyl chlorides is known to be solvolyzed through a borderline mechanism. ${ }^{10}$ There have been, however, much dispute over the mechanism as to whether it is an ionization $\left(p-\mathrm{OCH}_{3}\right.$ and $\left.p-\mathrm{CH}_{3}\right)$ or a borderline $(\mathrm{H}$ and $p-\mathrm{Cl})$ or an addition-elimination pathway $\left(p-\mathrm{NO}_{2}\right) .{ }^{10} \mathrm{~A}$ particularly important system which contains carbonyl carbon is ArCOCl; alkyl and aromatic acyl chlorides ${ }^{10-12}$ are important acyl transfer reagents in organic synthesis and nucleophilic substitution reactions. Solvent effects and LFERs in the solvolyses of alkyl and aromatic acyl halides, especially benzoyl chlorides, ${ }^{11}$ phenyl chloroformates, ${ }^{12}$ and ethyl and phenyl chlorothioformates, ${ }^{13}$ have received much attention, but little work has been done on the solvent effect on mixed solvents, especially for solvolyses of $N$-alkyl carbonyl chloride. In this work, we determined rate constants for solvolyses of 4-morpholinecarbonyl chloride (MPC) with $N$-alkyl group in aqueous binary solvents of acetone, ethanol, methanol, methanol-d, 2,2,2-trifluoroethanol (TFE), pure water, and $\mathrm{D}_{2} \mathrm{O}$ at various temperatures. Mechanistic variation and/or transition state variation are also discussed in terms of the one-term (simple) equation, two-term (extended) Grunwald-Winstein equation, $Z$ values, kinetic solvent isotope effects (KSIE) and activation parameters.<smiles></smiles>

\section{Results and Discussion}

The specific rates of solvolysis of MPC in the ethanol, methanol, pure water, and aqueous binary solvents of ethanol, 
Table 1. Specific rates of solvolysis $\left(\mathrm{k}^{-1} \mathrm{~s}^{-1}\right)$ of 4-morpholinecarbonyl chloride in binary solvent mixture at $35.0^{\circ} \mathrm{C}$

\begin{tabular}{cccc}
\hline Solvent $^{d}$ & $k\left(\mathrm{~s}^{-1}\right)$ & $N_{\mathrm{T}}{ }^{a}$ & $Y_{\mathrm{Cl}}{ }^{b}$ \\
\hline $100 \% \mathrm{EtOH}$ & $1.35 \times 10^{-5}$ & 0.37 & -2.52 \\
$90 \% \mathrm{EtOH}$ & $7.67 \times 10^{-5}$ & 0.16 & -0.94 \\
$80 \% \mathrm{EtOH}$ & $2.58 \times 10^{-4}$ & 0.00 & 0.00 \\
$70 \% \mathrm{EtOH}$ & $6.70 \times 10^{-4}$ & -0.20 & 0.78 \\
$60 \% \mathrm{EtOH}$ & $1.43 \times 10^{-3}$ & -0.39 & 1.38 \\
$50 \% \mathrm{EtOH}$ & $2.86 \times 10^{-3}$ & -0.58 & 2.02 \\
$40 \% \mathrm{EtOH}$ & $5.93 \times 10^{-3}$ & -0.74 & 2.75 \\
$30 \% \mathrm{EtOH}$ & $1.20 \times 10^{-2}$ & -0.93 & 3.53 \\
$20 \% \mathrm{EtOH}$ & $2.13 \times 10^{-2}$ & -1.16 & 4.09 \\
$100 \% \mathrm{H} 2 \mathrm{O}$ & $5.50 \times 10^{-2}$ & -1.38 & 4.57 \\
$100 \% \mathrm{MeOH}$ & $9.79 \times 10^{-5}$ & 0.17 & -1.17 \\
$90 \% \mathrm{MeOH}$ & $2.58 \times 10^{-4}$ & -0.01 & -0.18 \\
$80 \% \mathrm{MeOH}$ & $5.80 \times 10^{-4}$ & -0.06 & 0.67 \\
$70 \% \mathrm{MeOH}$ & $1.29 \times 10^{-3}$ & -0.40 & 1.46 \\
$60 \% \mathrm{MeOH}$ & $2.55 \times 10^{-3}$ & -0.54 & 2.07 \\
$50 \% \mathrm{MeOH}$ & $4.69 \times 10^{-3}$ & -0.57 & 2.70 \\
$40 \% \mathrm{MeOH}$ & $8.55 \times 10^{-3}$ & -0.87 & 3.25 \\
$30 \% \mathrm{MeOH}$ & $1.42 \times 10^{-2}$ & -1.06 & 3.73 \\
$20 \% \mathrm{MeOH}$ & $2.42 \times 10^{-2}$ & -1.23 & 4.10 \\
$87 \% \mathrm{Acetone}$ & $1.46 \times 10^{-5}$ & -0.34 & -1.81 \\
$80 \% \mathrm{Acetone}$ & $5.37 \times 10^{-5}$ & -0.37 & -0.83 \\
$75 \% \mathrm{Acetone}$ & $1.31 \times 10^{-4}$ & $-0.39^{c}$ & $-0.28^{c}$ \\
$63 \% \mathrm{Acetone}$ & $6.14 \times 10^{-4}$ & $-0.54^{c}$ & $0.62^{c}$ \\
$52 \% \mathrm{Acetone}$ & $1.76 \times 10^{-3}$ & $-0.68^{c}$ & $1.45^{c}$ \\
$42 \% \mathrm{Acetone}$ & $4.19 \times 10^{-3}$ & $-0.81^{c}$ & $2.21^{c}$ \\
$97 \% \mathrm{TFE}(\mathrm{w} / \mathrm{w})$ & $8.39 \times 10^{-5}$ & -3.30 & 2.83 \\
$80 \% \mathrm{TFE}(\mathrm{w} / \mathrm{w})$ & $4.80 \times 10^{-4}$ & -2.19 & 2.90 \\
$50 \% \mathrm{TFE}(\mathrm{w} / \mathrm{w})$ & $3.38 \times 10^{-3}$ & -1.73 & 3.16 \\
\hline
\end{tabular}

${ }^{a}$ From ref. $8 ;{ }^{b}$ From ref. $2 ;{ }^{c}$ From ref. $18(\mathrm{~g}) ;{ }^{d}$ Volume/volume basis at $25.0^{\circ} \mathrm{C}$, except for TFE- $\mathrm{H}_{2} \mathrm{O}$ mixtures, which are on a weight/weight basis.

methanol, trifluoroethanol (TFE), and acetone at $35.0{ }^{\circ} \mathrm{C}$ are summarized in Table 1. Rate constants for the reaction in deuterated solvent $\left(\mathrm{D}_{2} \mathrm{O}\right.$ and $\left.\mathrm{MeOD}\right)$ were also determined to examine isotope effects. Additional rate constants were measured to obtain thermodynamic parameters of activation such as enthalpies of activation and entropies of activation which are summarized in Table 2.

As shown in Table 1, the first-order rate constants increase in the order TFE-water $<$ acetone-water $<$ ethanol-water $<$ methanol-water. The rate constants also increase as the water content in the mixed solvents increases, indicating that the reaction rate is accelerated by the solvent with higher ionizing power $Y$, except $97 \%$ TFE- $\mathrm{H}_{2} \mathrm{O}$ and $80 \%$ TFE- $\mathrm{H}_{2} \mathrm{O}$ mixtures. The first-order rate constants increase as the ionizing power $Y$ changes from a lower value to a higher one, i.e., $k_{1}$ increases from $0.00135 \times 10^{-2}$ to $5.50 \times 10^{-2} \mathrm{~s}^{-1}$ as the $Y$ changes from $-2.52(100 \% \mathrm{EtOH})$ to $4.57\left(\mathrm{H}_{2} \mathrm{O}\right)^{1,5}$ for the solvolyses of MPC (increases 4000 fold). This means that the rate is remarkably affected by the solvent with higher ionizing power $Y$, suggesting that bond breaking in the transition state is significantly importance. The observed first-order rate constants for benzyl chlorides, $p$-methoxybenzoyl chloride and thenoyl chloride
Table 2. Specific rate $\left(k / \mathrm{s}^{-1}\right)$ of solvolysis for 4-morpholinecarbonyl chloride and activation parameters

\begin{tabular}{|c|c|c|c|c|}
\hline Solvent $^{b}$ & $\mathrm{~T}\left({ }^{\circ} \mathrm{C}\right)$ & $k\left(\mathrm{~s}^{-1}\right)$ & $\begin{array}{c}\Delta H^{\ddagger} \\
(\mathrm{kcal} / \mathrm{mol})^{a}\end{array}$ & $\begin{array}{c}-\Delta S^{\ddagger} \\
(\mathrm{cal} / \mathrm{mol} \mathrm{K})^{a}\end{array}$ \\
\hline $80 \% \mathrm{EtOH}$ & $\begin{array}{l}25 \\
35 \\
45\end{array}$ & $\begin{array}{l}8.12 \times 10^{-5} \\
2.58 \times 10^{-4} \\
8.39 \times 10^{-4}\end{array}$ & 20.5 & 8.5 \\
\hline $50 \% \mathrm{EtOH}$ & $\begin{array}{l}25 \\
35 \\
45\end{array}$ & $\begin{array}{l}9.24 \times 10^{-4} \\
2.86 \times 10^{-3} \\
8.15 \times 10^{-3}\end{array}$ & 19.3 & 7.8 \\
\hline $100 \% \mathrm{MeOH}$ & $\begin{array}{l}25 \\
35 \\
45\end{array}$ & $\begin{array}{l}3.11 \times 10^{-5} \\
9.79 \times 10^{-5} \\
2.89 \times 10^{-4}\end{array}$ & 19.5 & 6.8 \\
\hline $80 \% \mathrm{MeOH}$ & $\begin{array}{l}25 \\
35 \\
45\end{array}$ & $\begin{array}{l}1.97 \times 10^{-4} \\
5.80 \times 10^{-4} \\
2.09 \times 10^{-3}\end{array}$ & 20.7 & 5.9 \\
\hline $50 \% \mathrm{MeOH}$ & $\begin{array}{l}25 \\
35 \\
45\end{array}$ & $\begin{array}{l}1.53 \times 10^{-3} \\
4.69 \times 10^{-3} \\
1.50 \times 10^{-2}\end{array}$ & 20.0 & 4.2 \\
\hline $80 \%$ Acetone & $\begin{array}{l}25 \\
35 \\
45\end{array}$ & $\begin{array}{l}2.09 \times 10^{-5} \\
5.37 \times 10^{-5} \\
2.07 \times 10^{-4}\end{array}$ & 20.1 & 12 \\
\hline $42 \%$ Acetone & $\begin{array}{l}25 \\
35 \\
45\end{array}$ & $\begin{array}{l}1.56 \times 10^{-3} \\
4.19 \times 10^{-3} \\
1.26 \times 10^{-2}\end{array}$ & 18.2 & 10 \\
\hline 97\% TFE(w/w) & $\begin{array}{l}25 \\
35 \\
45\end{array}$ & $\begin{array}{l}2.32 \times 10^{-5} \\
8.42 \times 10^{-5} \\
2.20 \times 10^{-4}\end{array}$ & 19.7 & 14 \\
\hline $80 \% \mathrm{TFE}(\mathrm{w} / \mathrm{w})$ & $\begin{array}{l}25 \\
35 \\
45\end{array}$ & $\begin{array}{l}1.43 \times 10^{-4} \\
4.80 \times 10^{-4} \\
1.51 \times 10^{-3}\end{array}$ & 20.7 & 6.7 \\
\hline
\end{tabular}

${ }^{a}$ Obtained from an Eyring plot and using also the specific rate at $25{ }^{\circ} \mathrm{C}$. ${ }^{b}$ Volume/volume basis at $25.0,35.0$, and $45.0{ }^{\circ} \mathrm{C}$, except for TFE- $\mathrm{H}_{2} \mathrm{O}$ mixtures, which are on a weight/weight basis.

which are known to react via an $\mathrm{S}_{\mathrm{N}} 1$ (ionization) and/or dissociative $S_{N} 2$ reaction mechanism varied over several thousandfold range. ${ }^{11(\mathrm{f}), 15}$ The rates of solvolysis (Table 1) have been analyzed in terms of the one-term and two-term Grunwald-Winstein equation [eqn. (1) and (2)].

With all 28 solvent systems included, very good correlations are obtained except 97\% TFE and 80\% TFE aqueous solvent mixture, with an $m$ values of $0.50 \pm 0.01(\mathrm{r}=0.987)$ for the one-term equation (Figure 1). The data points for the $97 \%$ TFE aqueous solvent mixtures exhibit deviations from the correlation of one-term Grunwald-Winstein plots for aqueous alcohol and acetone. Greater rate constants in $40 \% v / v$ ethanol-water than in $97 \% \mathrm{w} / \mathrm{w}$ trifluoroethanol-water (solvent of approximately equal ionizing power) show the importance of nucleophilic solvent assistance $\left(\mathrm{S}_{\mathrm{N}} 2\right.$ or addition-elimination character). ${ }^{4(\mathrm{c}), 9,12(\mathrm{~d}), 18}$ Rate ratio in two solvents which have nearly same $Y_{\mathrm{Cl}}$ value, i.e., the same degree of solvent assistance for bond cleavage but large different nucleophilicity provides measures of the minimum extent of nucleophilic solvent assistance (e.g., $\left[k_{40 \mathrm{EW}} /\right.$ 


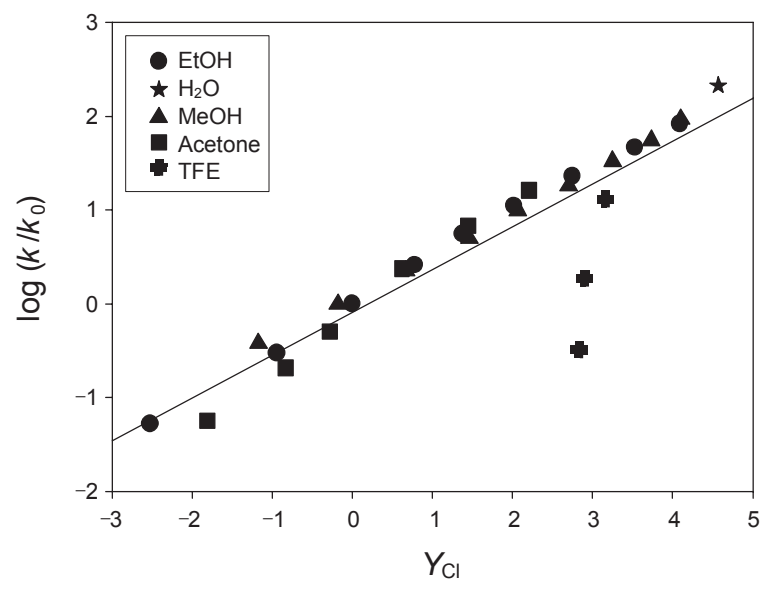

Figure 1. The plot of $\log \left(k / k_{0}\right)$ for solvolyses of 4-morpholinecarbonyl chloride against $0.46 Y_{\mathrm{Cl}}$ at $35^{\circ} \mathrm{C}(r=0.904)$.

$\left.\left.k_{97 \mathrm{TFE}}\right]=71\right) .{ }^{16}$ The $m$ value and $k_{40 \mathrm{EW}} / k_{97 \mathrm{TFE}}$ ratio imply that the solvolyses of MPC in the binary aqueous solvent mixtures proceed through $\mathrm{S}_{\mathrm{N}} 1 / \mathrm{S}_{\mathrm{N}} 2$ and/or ionization/(addition-elimination), $[\mathrm{I} /(\mathrm{A}-\mathrm{E})]^{17}$ pathways rather than through an $\mathrm{S}_{\mathrm{A}} \mathrm{N}$ or addition-elimination channel. ${ }^{4(\mathrm{c}), 9,12(\mathrm{~d}), 18}$

An analysis using the two-term (or extended) Grunwald-Winstein equation of the data for the specific rates of solvolyses of MPS in 28 binary solvent mixtures leads to a very good linear correlation with values of $0.71 \pm 0.05$ for $l, 0.65 \pm 0.02$ for $m$, $0.11 \pm 0.04$ for $c$ and 0.991 for the correlation coefficient. Twoterm Grunwald-Winstein plots for the specific rates of solvolyses of MPC without the $97 \%$ TFE and $80 \%$ TFE aqueous solvents data points lead to a excellent linear correlation with values of $0.31 \pm 0.11$ for $l, 0.57 \pm 0.03$ for $m, 0.03$ for $c$ and 0.995 for the correlation coefficient. The results of the correlation are presented in Figures 2 and 3 and reported in Table 3, together with the corresponding parameters obtained in the analyses of

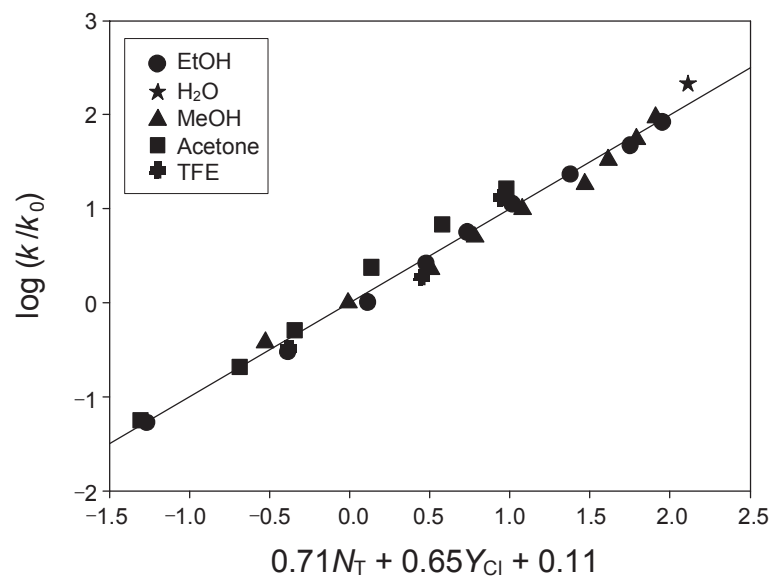

Figure 2. Plots of $\log \left(k / k_{0}\right)$ for solvolyses of 4-morpholinecarbonyl chloride against $0.71 N_{\mathrm{T}}+0.65 Y_{\mathrm{Cl}}+0.11$ at $35.0{ }^{\circ} \mathrm{C}(r=0.991)$.

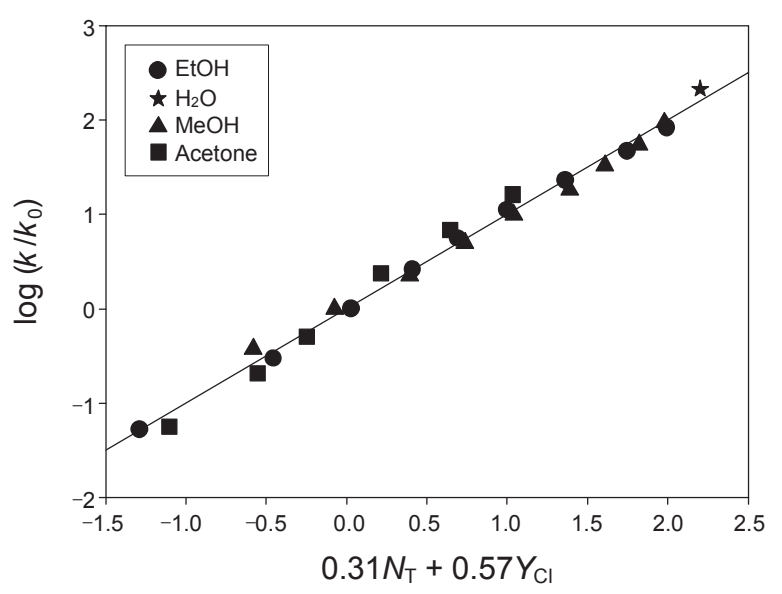

Figure 3. Plots of $\log \left(k / k_{0}\right)$ for solvolyses of 4-morpholinecarbonyl chloride against $0.31 N_{\mathrm{T}}+0.57 Y_{\mathrm{Cl}}$ at $35.0{ }^{\circ} \mathrm{C}(r=0.995)$.

Table 3. Coefficients from the extended Grunwald-Winstein correlations of the specific rates of solvolysis of 4-morpholinecarbonyl chloride at $35.0{ }^{\circ} \mathrm{C}$ and a comparison with coefficients from the correlations for other acyl chlorides

\begin{tabular}{cccccrc}
\hline Substrate & Mech $^{a}$ & $n^{b}$ & $l^{c}$ & $m^{c}$ & $c^{c}$ & $R^{d}$ \\
\hline $\mathrm{C}_{6} \mathrm{H}_{5} \mathrm{COCl}$ & $\mathrm{I}$ & $32^{e}$ & $0.47 \pm 0.03$ & $0.79 \pm 0.02$ & $-0.49 \pm 0.17$ & 0.990 \\
$p-\mathrm{CH}_{3} \mathrm{OC}_{6} \mathrm{H}_{4} \mathrm{COCl}$ & $\mathrm{I}$ & $37^{e}$ & $0.31 \pm 0.05$ & $0.81 \pm 0.02$ & $0.08 \pm 0.21$ & 0.989 \\
$p-\mathrm{NO}_{2} \mathrm{C}_{6} \mathrm{H}_{4} \mathrm{COCl}$ & $\mathrm{A}-\mathrm{E}$ & $34^{e}$ & $1.78 \pm 0.08$ & $0.54 \pm 0.04$ & $0.11 \pm 0.37$ & 0.990 \\
$\mathrm{BzOCOCl}^{j}$ & $\mathrm{~A}-\mathrm{E}$ & 15 & $1.95 \pm 0.16$ & $0.57 \pm 0.05$ & $0.16 \pm 0.15$ & 0.966 \\
$\mathrm{BzOCOCl}^{j}$ & $\mathrm{I}$ & 11 & $0.25 \pm 0.05$ & $0.66 \pm 0.06$ & $-2.05 \pm 0.11$ & 0.976 \\
$\mathrm{EtOCOCl}^{i}$ & $\mathrm{~A}-\mathrm{E}$ & 28 & $1.56 \pm 0.09$ & $0.55 \pm 0.03$ & $0.19 \pm 0.24$ & 0.967 \\
$\mathrm{EtOCOCl}^{i}$ & $\mathrm{I}$ & 7 & $0.69 \pm 0.13$ & $0.82 \pm 0.16$ & $-2.40 \pm 0.27$ & 0.946 \\
$\mathrm{PhOCOCl}^{j}$ & $\mathrm{~A}-\mathrm{E}$ & 21 & $1.68 \pm 0.10$ & $0.57 \pm 0.06$ & $0.12 \pm 0.41$ & 0.973 \\
$2-\mathrm{AdOCOCl}$ & $\mathrm{I}$ & 19 & $\sim 0$ & $0.47 \pm 0.03$ & $0.11 \pm 0.19$ & 0.970 \\
$\mathrm{EtSCOCl}$ & $\mathrm{I}$ & 19 & $0.66 \pm 0.08$ & $0.93 \pm 0.07$ & $-0.16 \pm 0.31$ & 0.961 \\
$\mathrm{PhSCOCl}$ & $\mathrm{A}-\mathrm{E}$ & $16^{m}$ & $1.74 \pm 0.17$ & $0.48 \pm 0.07$ & $0.19 \pm 0.23$ & 0.946 \\
$\mathrm{PhSCOCl}$ & $\mathrm{I}$ & $6^{m}$ & $0.62 \pm 0.08$ & $0.92 \pm 0.11$ & $-2.29 \pm 0.13$ & 0.983
\end{tabular}

${ }^{a}$ The two reaction channels are designated as addition-elimination (A-E) and ionization (I). ${ }^{b}$ Number of solvent systems included in the correlation. ${ }^{c}$ With associated standard errors, those associated with the $c$ values being the standard errors of the estimate. ${ }^{d}$ Correlation coefficient. ${ }^{e}$ Data from refs. 3 , 10 , 11(a), 11(d), 11(e),11(f), 18(i), and 22(d). ${ }^{f}$ Values from ref. 18(k). ${ }^{i}$ Values from ref. 13(b). ${ }^{j}$ Values from ref. 18(j). ${ }^{k}$ Values from ref. $18(\mathrm{i}) .{ }^{l}$ Values from ref. $13(\mathrm{~b}) .{ }^{m}$ Values from ref. $7(\mathrm{~d})$. 


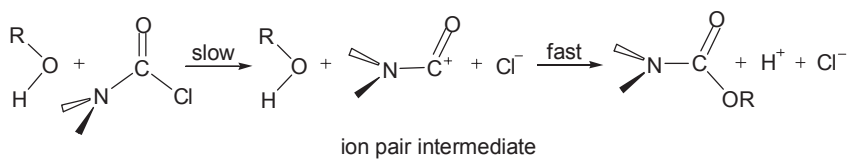

Scheme 1

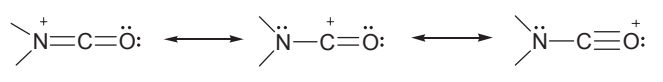

Scheme 2

earlier studied substrates. The $l / m$ ratio has been suggested as a useful mechanistic criterion and the values in Table 3 were divided nicely into three classes with values of 1.9 to 3.4 for those entries postulated to represent addition-elimination (A-E), values below 0.84 for those believed to represent ionization (I), and values of 0.84 to 1.9 for those postulated to represent $\mathrm{I} /(\mathrm{A}-\mathrm{E})$ mechanism. ${ }^{9}$ For MPC, the $l / m$ values of 1.09 (28 all solvents) and 0.54 (excluded $97 \%$ TFE and $80 \%$ TFE data points) are very similar to those previously observed $l / m$ values for the solvolyses of $p$-methoxybenzoyl chloride, ${ }^{10}$ phenyl chloroformate, ${ }^{12}$ and phenyl chlorothioformate, ${ }^{13(a)}$ which have been shown to solvolyze with the ionization step of an I and/or I/(A-E) pathway. ${ }^{9,17}$ The mechanism leads to a changeover from a dominant A-E pathway to a I pathway (Scheme 1), because the dominant resonance contribution proposed for benzoyl cation will be operative for the MPC cation, with the positive charge substantially transferred within the carbonyl group from the carbon to the nitrogen atom (Scheme 2). Ion pair intermediate can be stabilization of the developing acylium ion by mesomeric interaction of the lone pair electrons on the nitrogen shown in Scheme 2. ${ }^{19}$ The first contributor will be dominant, because nitrogen atom can carry a positive charge in onium-type structure than oxygen, ${ }^{20}$ and also nitrogen atom can give better $\pi$ electron donation effect than oxygen atom. In turn, this will lead to an enhanced stability for the resonance hybrid.

The solvent deuterium isotope effect has previously been studied for solvolyses of $p$-methoxybenzoyl chlorides and $p$-methoxybenzyl chloride. ${ }^{9,11(\mathrm{f}), 23}$ In pure methanol, the $k_{\mathrm{MeOH}} / k_{\mathrm{MeOD}}$ ratio was 1.22 (see Table 4 ) at $25{ }^{\circ} \mathrm{C}$ for a series of substrates believed to react by the $\mathrm{S}_{\mathrm{N}} 1$ or ionization mechanism. ${ }^{8,11(\mathrm{f}), 23} \mathrm{In}$ pure water, the $k_{\mathrm{H}_{2} \mathrm{O}} / k_{\mathrm{D}_{2} \mathrm{O}}$ ratio was 1.25 and 1.1 for solvolyses of isopropyl chloroformate ${ }^{8}$ and diphenylcarbamoyl chloride, ${ }^{19(\mathrm{c}),(\mathrm{d})}$ respectively, which are believed to react by the $\mathrm{S}_{\mathrm{N}} 1$ or ionization mechanism. The solvent deuterium isotope effect values (Table 4) for the hydrolysis of MPC of $k_{\mathrm{H}_{2} \mathrm{O}} / k_{\mathrm{D}_{2} \mathrm{O}}=1.27$ and for

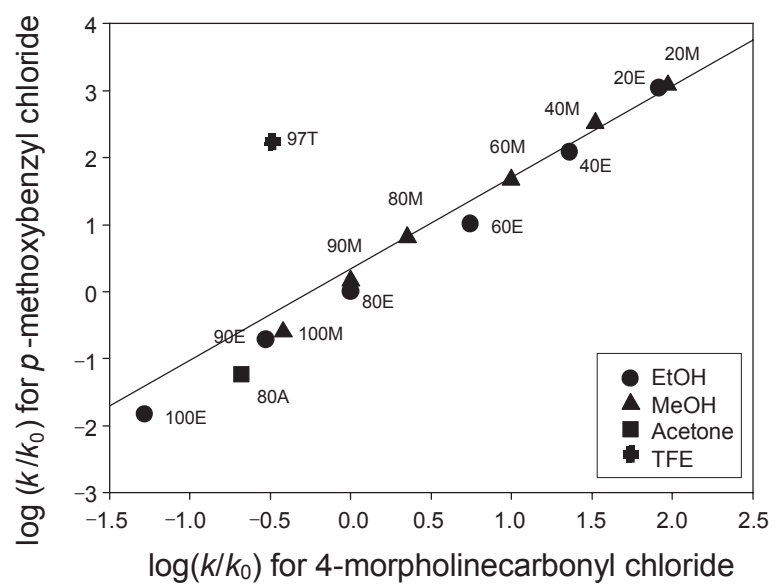

Figure 4. Correlation of logarithms of rate constants for solvolyses of $p$-methoxybenzyl chloride ${ }^{11(f)} v s$. solvolyses of 4-morpholinecarbonyl chloride at $35.0{ }^{\circ} \mathrm{C}(r=0.879)$.

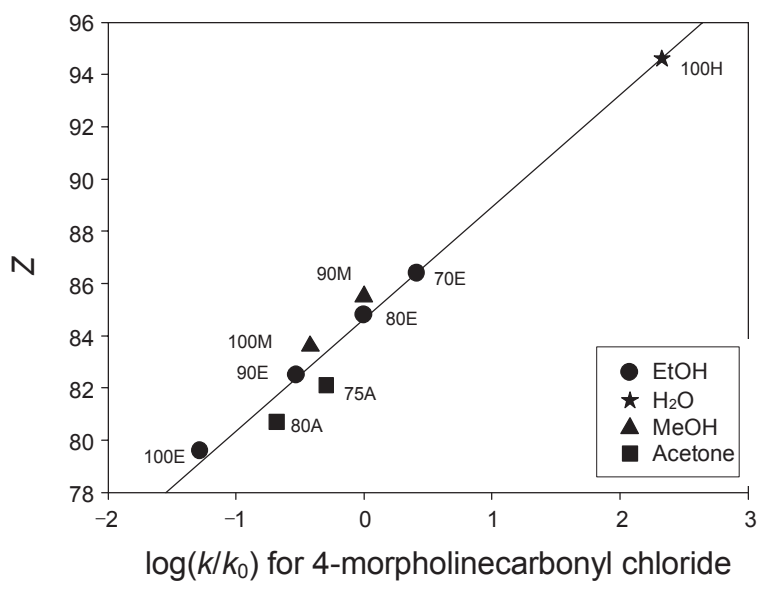

Figure 5. Correlation of $Z^{20}$ values $v s$. logarithms of rate constants for solvolyses of 4-morpholinecarbonyl chloride ${ }^{b}$ at $35.0^{\circ} \mathrm{C}(r=0.986)$.

the methanolysis of MPC of $k_{\mathrm{MeOH}} / k_{\mathrm{MeOD}}=1.21$ are typical magnitudes of the $\mathrm{S}_{\mathrm{N}} 1$ or ionization mechanism.

Good correlations showing negligible dispersion can also be seen for solvolyses of $p$-methoxybenzoyl chloride $v$ s. solvolyses of MPC (Figure 4), except that there is a significant deviation for $97 \% \mathrm{TFE} /$ water. The deviation shows that the reaction path of solvolyses of MPC differs from that of $p$-methoxybenzoyl chloride because the TFE has lower nucleophilicity and higher electrophilicity though the solvent ionizing power of 97\% TFE

Table 4. Rate constants and kinetic solvent isotope effects (KSIE) in methanol and water

\begin{tabular}{|c|c|c|c|}
\hline Substrate & $\mathrm{k}\left(\mathrm{s}^{-1}\right)^{c}(\mathrm{MeOH})$ & $\mathrm{k}\left(\mathrm{s}^{-1}\right)^{c}(\mathrm{MeOD})$ & $\operatorname{KSIE}^{d}$ \\
\hline$p$-methoxybenzyl chloride ${ }^{a}$ & $(2.86 \pm 0.01) \times 10^{-4}$ & $(2.35 \pm 0.05) \times 10^{-4}$ & $1.22 \pm 0.04$ \\
\hline$p$-methoxybenzoyl chloride ${ }^{a}$ & $(1.13 \pm 0.01) \times 10^{-2}$ & $(9.25 \pm 0.07) \times 10^{-3}$ & $1.22 \pm 0.02$ \\
\hline 4-morpholinecarbonyl chloride ${ }^{b}$ & $\begin{array}{c}(9.79 \pm 0.01) \times 10^{-5} \\
\left(\mathrm{H}_{2} \mathrm{O}\right)\end{array}$ & $\begin{array}{c}(8.11 \pm 0.05) \times 10^{-5} \\
\left(\mathrm{D}_{2} \mathrm{O}\right)\end{array}$ & $1.21 \pm 0.02$ \\
\hline 4-morpholinecarbonyl chloride ${ }^{b}$ & $(5.50 \pm 0.03) \times 10^{-2}$ & $(4.32 \pm 0.02) \times 10^{-2}$ & $1.27 \pm 0.02$ \\
\hline
\end{tabular}

${ }^{a}$ Values from Ref. 11(f). ${ }^{b}$ This work. ${ }^{c}$ Standar deviation. ${ }^{d}$ Standard error. 
is similar to the that of $40 \% \mathrm{v} / \mathrm{v}$ ethanol-water. The solvatochromic parameter $Z,{ }^{11(\mathrm{f}), 21}$ a scale of solvent polarity based on the solvent dependence of intermolecular charge-transfer transition in the prydinium salt, ${ }^{11(\mathrm{f}), 21}$ shows a good correlation with solvolyses of MPC (Figure 5). These results indicate that the solvolyses of MPC proceed by dissociative $\mathrm{S}_{\mathrm{N}} 2$ predominantly or $\mathrm{S}_{\mathrm{N}}$ 1(ionization) pathway with a acylium ion pair intermediate or loose $\mathrm{S}_{\mathrm{N}} 2$ transition sate, supporting that acylium ion pair intermediate is stabilized by solvent polarity.

The activation parameters for solvolyses of MPC in aqueous binary solvent mixtures at $25^{\circ} \mathrm{C}$ are summarized in Table 2 . The relatively small negative $\Delta S^{\neq}$and large positive $\Delta H^{\neq}$support that the solvolytic reaction proceeds through a typical dissociative $\mathrm{S}_{\mathrm{N}} 2$ or $\mathrm{S}_{\mathrm{N}} 1$ (ionization) pathway. ${ }^{22,23}$

\section{Experimental Section}

Material. 4-Morpholinecarbonyl chloride (MPC) is a commercial grade (Merck GR-grade $>99 \%$ ). Merck GR-grade $(<0.1 \%$ $\mathrm{H}_{2} \mathrm{O}$ ) acetone, ethanol, methanol and trifluoroethanol were used without further purification. $\mathrm{D}_{2} \mathrm{O}$ and $\mathrm{CH}_{3} \mathrm{OD}$ were from Aldrich $(99.9 \%$ D). Distilled water was redistilled with Buchi Fontavapor 210 and treated using ELGA UHQ PS to obtain specific conductivity of less than $1.0 \times 10^{-6} \mathrm{mhos} / \mathrm{cm}$.

Rate measurements and product identification. Rates were measured conductimetrically at least in duplicate as in the previous work. ${ }^{4}$ Activation parameters were determined using the Arrhenius and Eyring equations. The solvolyses product was identified by ${ }^{1} \mathrm{H}$ NMR spectrum.

\section{References}

1. (a) Grunwald, E.; Winstein, S. J. Am. Chem. Soc. 1948, 70, 846. (b) Winstein, S.; Grunwald, E.; Jones, H. W. J. Am. Chem. Soc. 1951, 73, 2700.

2. (a) Bentley, T. W.; Llewellyn, G. Prog. Phys. Org. Chem. 1990, 17, 121. (b) Kevill, D. N.; D’Souza, M. J. J. Chem. Res. Synop. 1993, 174. (c) Lomas, J. S.; D’Souza, M. J.; Kevill, D. N. J. Am. Chem. Soc. 1995, 117, 5891.

3. (a) Bentley, T. W.; Carter, G. E.; Harris, H. C. J. Chem. Soc., Chem. Commun. 1984, 388. (b) Bentley, T. W.; Carter, G. E.; Harris, H. C. J. Chem. Soc., Perkin Trans. 2 1985, 983. (c) Bentley, T. W.; Harris, H. C. J. Chem. Soc., Perkin Trans. 2 1986, 619. (d) Bentley, T. W.; Harris, H. C.; Koo, I. S. J. Chem. Soc., Perkin Trans. 2 1988, 783. (e) Swain, C. G.; Mosely, R. B.; Bown, D. E. J. Am. Chem. Soc. 1955, 77, 3731.

4. (a) Koo, I. S.; Bentley, T. W.; Kang, D. H.; Lee, I. J. Chem. Soc., Perkin Trans. 2 1991, 173. (b) Koo, I. S.; Bentley, T. W.; Llewellyn, G.; Yang, K. J. Chem. Soc., Perkin Trans. 2 1991, 1175. (c) Koo, I. S.; Kwon, E.; Choi, H.; Yang, K.; Park, J. K.; Lee, J. P.; Lee, I.; Bentley, T. W. Bull. Korean Chem. Soc. 2007, 28, 2377.

5. (a) Winstein, S.; Fainberg, A. H.; Grunwald, E. J. Am. Chem. Soc. 1957, 79, 4146. (b) Fainberg, A. H.; Winstein, S. J. Am. Chem. Soc. 1957, 79, 1957.

6. (a) Koo, I. S.; Yang, K.; Kang, K.; Lee, I. Bull. Korean Chem. Soc. 1998, 19, 968. (b) Koo, I. S.; Lee, J. S.; Yang, K.; Kang, K.; Lee, I. Bull. Korean Chem. Soc. 1999, 20, 573.

7. (a) Kevill, D. N.; Ismail, NHJ.; D'Souza, M. J. J. Org. Chem. Soc. 1994, 59, 6303. (b) Kevill, D. N.; D'Souza, M. J. J. Chem. Soc., Perkin Trans. 2 1995, 973. (c) Kevill, D. N.; D’Souza, M. J. J. Chem. Soc., Perkin Trans. 2 1997, 257. (d) Kevill, D. N.; Bond,
M. W.; D'Souza, M. J. J. Org. Chem. 1997, 62, 7869.

8. (a) Kevill, D. N. Development and Uses of Scales of Solvent Nucleophilicity. In Advances in Quantitative Structure-Property Relationships; Charton, M., Ed.; JAI Press: Greenwich, CT, 1996; Vol. 1, 81-115. (b) Kevill, D. N.; Anderson, S. W. J. Org. Chem. 1991, 56, 1845.

9. (a) Kevill, D. N.; D'Souza, M. J. J. Chem. Soc., Perkin Trans. 2 2002, 240. (b) Kyong, J. B.; Rhu, C. J.; Kim, Y. G.; Kevill, D. N. J. Phys. Org. Chem. 2007, 20, 525.

10. Kevill, D. N.; D’Souza, M. J. J. Phys. Org. Chem. 2002, 15, 881.

11. (a) Lee, I.; Koo, I. S.; Sohn, S. C.; Lee, H. H. Bull. Korean Chem. Soc. 1982, 3, 92. (b) Lee, I.; Sung, D. D.; Uhm, T. S.; Ryu, Z. H. J. Chem. Soc., Perkin Trans. 2 1989, 1697. (c) Bentley, T. W.; Harris, H. C.; Koo, I. S. J. Chem. Soc., Perkin Trans. 2 1988, 783. (d) Bentley, T. W.; Harris, H. C. J. Org. Chem. 1988, 53, 724. (e) Bentley, T. W.; Koo, I. S. J. Chem. Soc., Perkin Trans. 2 1989, 1385. (f) Bentley, T. W.; Koo, I. S.; Norman, S. J. J. Org. Chem. 1991, 56, 1604.

12. (a) Koo, I. S.; Lee, J. S.; Yang, K.; Kang, K.; Lee, I. Bull. Korean Chem. Soc. 1999, 20, 573. (b) Koo, I. S.; Yang, K.; Koo, J. C.; Park, J. K.; Lee, I. Bull. Korean Chem. Soc. 1997, 18, 1017. (c) Koo, I. S.; Yang, K.; Kang, K.; Lee, I. Bull. Korean Chem. Soc. 1998, 19, 968. (d) Kevill, D. N.; Kim, J. C.; Kyong, J. B. J. Chem. Research 1999, 150.

13. (a) An, S. K.; Yang, T. S.; Cho, J. M.; Yang, K.; Lee, J. P.; Bentley, T. W.; Lee, I.; Koo, I. S. Bull. Korean Chem. Soc. 2002, 23, 1445. (b) Kevill, D. N.; D'Souza, M. J. J. Org. Chem. 1998, 63, 2120.

14. Koo, I. S.; Bentley, T. W.; Lee, I. J. Korean Chem. Soc. 1990, 34 , 304.

15. Oh, J.; Yang, K.; Koo, I. S.; Lee, I. J. Chem. Res. 1993, 310.

16. Bentley, T. W.; Llewellyn, G.; Ryu, Z. H. J. Org. Chem. 1998, 63, 4654.

17. $\mathrm{I} /(\mathrm{A}-\mathrm{E})$ pathway terminology is very similar to $\mathrm{S}_{\mathrm{N}} 1 / \mathrm{S}_{\mathrm{N}} 2$.

18. (a) McLennan, D. J.; Martin, P. L. J. Chem. Soc., Perkin Trans. 2 1982, 1099. (b) Liu, K.-T.; Duann, Y. F.; Hou, S. H. J. Chem. Soc., Perkin Trans. 2 1998, 2181. (c) Liu, K.-T.; Chen, H.-I. J. Chem. Soc., Perkin Trans. 2 2000, 893. (d) Ryu, Z. H.; Shin, S. H.; Lim, G. T.; Lee, J. P. Bull. Korean Chem. Soc. 2004, 25, 307. (e) Koo, I. S.; An, S. K.; Yang, K.; Koh, H. J.; Choi, M. H.; Lee, I. Bull. Korean Chem. Soc. 2001, 22, 842. (f) Ryu, Z. H.; Bentley, T. W. Bull. Korean Chem. Soc. 2008, 29, 2145. (g) Kevill, D. N.; Ryu, Z. H.; Niedermeyer, M. A.; Koyoshi, F.; D’Souza, M. J. J. Phys. Org. Chem. 2007, 20, 431. (h) Ryu, Z. H.; Lee, S. W.; D'Souza, M. J.; Yaakoubd, L.; Feld, S. E.; Kevill, D. N. Int. J. Mol. Sci. 2008, 9, 2639. (i) Kyong, J. B.; Yoo, J. S.; Kevill, D. N. J. Org. Chem. 2003, 68, 3425. (j) Kevill, D. N.; D'Souza, M. J. J. Chem. Soc., Perkin Trans. 2 1997, 1721. (k) Kyong, J. B.; Won, H.; Kevill, D. N. Int. J. Mol. Sci. 2005, 6, 87. (1) Kyong, J. B.; Kim, Y. G.; Kim, D. K.; Kevill, D. N. Bull. Korean Chem. Soc. 2000, 21, 662. (m) Kyong, J. B.; Park, B. C.; Kim, C. B.; Kevill, D. N. J. Org. Chem. 2000, 65, 8051.

19. (a) Johnson, S. Adv. Phys. Org. Chem. 1967, 5, 237. (b) Bacaloglu, R.; Dăescu, C.; Ostrogovich, G. J. Chem. Soc., Perkin Trans. 2 1972, 1011. (c) D’Souza, M. J.; Kevill, D. N.; Bentley, T. W.; Devaney, A. C. J. Org. Chem. 1995, 60, 1632. (d) Kevill, D. N.; Bond, M. W.; D'Souza, M. J. J. Phys. Org. Chem. 1998, 11, 273.

20. Kevill, D. N.; Rudolph, T. M.; D’Souza, M. J. J. Phys. Org. Chem. 2000, 13, 192

21. (a) Kosower, E. M. J. Am. Chem. Soc. 1958, 80, 3253. (b) Kosower, E. M. J. Am. Chem. Soc. 1958, 80, 3267.

22. Frost, A.; Pearson, R. G. Kinetic and Mechanism, 2nd ed.; Wiley: New York, 1961; Chap 7.

23. (a) Queen, A. Can. J. Chem. 1967, 45, 1619. (b) Yew, K. H.; Koh, H. J.; Lee, H. W. J. Chem. Soc., Perkin Trans. 2 1995, 2263. (c) Koo, I. S.; Yang, K.; Kang, K.; Oh, H. J.; Lee, I. Bull. Korean Chem. Soc. 1996, 17, 520. (d) Kevill, D. N.; D’Souza, M. J. J. Org. Chem. 1998, 63, 2120. 